\title{
Inclusão na educação física escolar na concepção dos escolares com deficiência visual
}

\author{
Edison Montenegro Alonso ${ }^{1}$ \\ Camila Lopes de Carvalho ${ }^{2}$ \\ Paulo Ferreira de Araújo² \\ Marina Brasiliano Salerno ${ }^{1}$
}

\section{RESUMO}

Introdução: O processo de inclusão escolar dos alunos com deficiência visual nas aulas de educação física reflete momentos históricos, bem como percepções e conceitos sociais. Objetivo: Assim, com este estudo, objetivamos analisar a inclusão nas aulas de Educação Física Escolar na concepção dos escolares com deficiência visual. Método: Em um estudo de caso, como coleta de dados foi empregada uma entrevista semiestruturada com dois alunos com deficiência visual adquirida, do ensino médio da rede pública de Campo Grande, Mato Grosso do Sul, Brasil. Os dados foram apreciados por meio de uma análise de conteúdo. Resultados: identificamos que a falta de acessibilidade arquitetônica se mostra recorrente, bem como momentos de não participação dos alunos durante as aulas devido à sua condição. Apesar de um dos participantes relatar se sentir acolhido pelo grupo e ter as atividades adaptadas pela professora, outro ainda se diz excluído e carente de atuação docente para facilitar sua participação. Os alunos clamam por maior participação nas aulas, participação esta alicerçada pela compreensão dos colegas sobre a sua condição, bem como uso do esporte adaptado como conteúdo de aula. Conclusão: Assim, a inclusão de alunos com deficiência nas aulas de Educação Física se encontra em processo de construção, com pontos positivos entremeados por dificuldades em sua consolidação.

Palavras-chave: Inclusão educacional. Pessoas com deficiência visual. Educação.

\footnotetext{
1 Universidade Federal de Mato Grosso do Sul.

2 Universidade Estadual de Campinas.

Correspondência:

Marina Brasiliano Salerno. Universidade Federal de Mato Grosso do Sul, Curso de Educação Física, Fundação Universidade Federal de Mato Grosso do Sul, Caixa Postal 549, CEP 79070900, Campo Grande, MS - Brasil, Email: marina.brasiliano@gmail.com
} 


\section{Inclusion in school physical education under the perception of visual disabled students}

\section{ABSTRACT}

Introduction: The school inclusion process of visually impaired students reflects several historical moments, revealing perceptions, concepts and understandings about different aspects that permeate society. Objective: Thus, with this study, we aim to analyze the inclusion in School Physical Education classes under the perception of the person with visual impairment. Method: In a case study, as data collection, a semi-structured interview was used with two students with acquired visual impairment, from public high school in Campo Grande, Mato Grosso do Sul, Brazil, who were appreciated for content analysis. Results: we identified a lack of architectural accessibility, which were still recurring, as well as moments of non-participation by students during classes due to their condition. Although one of the participants reported feeling welcomed by the group and having the activities adapted by the teacher, another one still says he is excluded and lacks teaching performance to facilitate his participation. Students call for greater participation in classes, participation based on the understanding of colleagues about their condition. Conclusion: Thus, the inclusion of students with disabilities in Physical Education classes is under construction, with positive points interspersed with difficulties in their consolidation.

Keywords: Mainstreaming (Education). Visually impaired persons. Education.

\section{Inclusión en la educación física escolar bajo la percepción de estudiantes con discapacidad visual}

\section{RESUMEN}

Introducción: El proceso de inclusión escolar de estudiantes con discapacidade visual refleja varios momentos históricos, percepciones, conceptos y entendimientos sociales. Objetivo: Con este estudio, nuestro objetivo es analizar la inclusión en las clases de educación física escolar bajo la percepción de la persona con discapacidad visual. Método: En un estudio de caso, como recopilación de datos, se utilizó una entrevista semiestructurada con dos estudiantes con discapacidad visual adquirida, de escuelas secundarias públicas en Campo Grande, Mato Grosso do Sul, Brasil, que fueron evaluados por análisis de contenido. Resultados: identificamos una falta de accesibilidad arquitectónica, que todavía era recurrente, así como momentos de no participación de los estudiantes durante las clases debido a su condición. Aunque uno de los participantes informó sentirse bienvenido por el grupo y que las actividades fueran adaptadas por el maestro, otro todavía dice que está excluido y que carece de rendimiento docente para facilitar su participación. Los estudiantes solicitan una mayor participación en las clases, participación basada en la comprensión de los colegas sobre su condición. Conclusión: Por lo tanto, la inclusión de estudiantes con discapacidades en las clases de Educación Física está en construcción, con puntos positivos intercalados con dificultades en su consolidación.

Palabras Clave: Propensión (Educación). Personas con daño visual. Educación. 


\section{INTRODUÇÃO}

O processo de implantação da inclusão escolar de pessoas com deficiência reflete fatos ocorridos em diversos momentos históricos, permeados por aspectos socioeconômicos e políticos. Ao longo dessa trajetória, a compreensão e os procedimentos destinados a esse público específico delinearam-se por atitudes predominantemente de menosprezo e exclusão, mas também galgou de tímida aceitação, tolerância, apoio e proximidade com a divindade, de acordo com diferentes constituições culturais (SILVA; SEABRA JUNIOR; ARAÚJO, 2008).

A partir do século XVII - e se ampliando no século XVIII -, surgiu uma preocupação de caráter humanista, alicerçada pelo avanço da ciência e da educação, que instigou a realização de diferentes ações destinadas ao atendimento da pessoa com deficiência. Inicialmente, essas pessoas foram recebidas em instituições especializadas, espaços que recebiam crianças, jovens e adultos com as mesmas condições de deficiência. Nesse início, tais ambientes possuíam função de acolhê-las sob uma perspectiva médica de busca por uma cura da sua condição. Não se alcançando esse objetivo, essas ações minimizaram-se atribuindo a esses locais, caráter assistencialista. No século XX, as discussões sobre a pessoa com deficiência retornaram. Dessa vez, apresentavam-se preocupações educacionais mais contundentes, devido às alterações sociopolíticas que destinaram maior atenção aos grupos minoritários, além do desenvolvimento das áreas da educação, da psicologia e da própria medicina (SMITH, 2008).

A partir de então, vivenciaram-se três fases em relação à participação social da pessoa com deficiência, que se refletiram diretamente no contexto escolar: a normalização, a integração e a inclusão (SILVA; SEABRA JUNIOR; ARAÚjO, 2008). Durante a normalização, em torno da década de 1950, o objetivo das instituições era preparar as pessoas com deficiência para a vida em sociedade. Entretanto, a interação dessas pessoas restringia-se àqueles que frequentavam esses espaços, ou seja, pessoas com a mesma condição de deficiência, profissionais e familiares. Entre as décadas de 1960 e 70, o princípio integracionista criticava esse isolamento social e passou a propor a inserção das pessoas com deficiência na sociedade. No entanto, cabia a elas se adaptarem a uma participação em um contexto já constituído (SILVA; SEABRA JUNIOR; ARAÚJO, 2008).

Sob a influência dessas ações, houve uma proposta inicial no cenário escolar de inserir a pessoa com deficiência em classes especiais. Assim, esses alunos foram alocados na escola em uma classe separada preparatória para que os que se mostrassem qualificados frequentassem a classe regular. Esse processo de integração, contudo, não levava em consideração as questões individuais da pessoa com deficiência, já que todas as adequações do processo 
educacional ficavam a cargo do próprio aluno (FONSECA,1991).

Esse espaço tornou-se motivo de estigmatização dos alunos com deficiência que não eram estimulados de acordo com as suas capacidades, mas sim comparados com um padrão de desempenho a ser alcançado, sem efetivamente interagir com os seus colegas sem deficiência. Apresentada como sendo de caráter transitório, a classe especial revelou-se um gueto que, ao invés de aproximar os alunos com deficiência das pessoas que frequentavam a escola regular, distanciava-os ainda mais (FONSECA, 1991).

Sob a influência de diferentes documentos internacionais elaborados após o ano de 1981 - considerado como o Ano Internacional da Pessoa Deficiente pela Organização das Nações Unidas (ONU) -, dispenderam-se reflexões sobre a forma como essa inserção vinha ocorrendo, inclusive no cenário escolar. A terceira e última fase, até o momento, constituiu-se com a denominação de inclusão, destacando a necessidade de permitir o acesso e a participação com qualidade da pessoa com deficiência em todos os contextos sociais, cabendo à sociedade se adaptar para acolher e permitir a atuação de todos (SILVA; SEABRA JUNIOR; ARAÚJO, 2008).

Dentre os documentos elaborados que sustentaram a defesa do princípio inclusivo, destaca-se a Declaração de Salamanca (BRASIL, 1994), que trouxe um direcionamento das ações para a adequação de estratégias segundo as necessidades de cada aluno. Essa declaração apontou para a necessidade de todas as pessoas, independentemente da faixa etária, serem abarcadas pelos programas e sistemas educacionais, bem como de receberem um ensino de qualidade e adaptado às suas necessidades. Tal documento impactou diretamente a reformulação das normas educacionais de vários países, como ao induzir a reformulação da Lei de Diretrizes e Bases da Educação Nacional do Brasil (LDB), em 1996.

Nesse contexto, almejou-se efetivar a inclusão escolar da pessoa com deficiência, que deveria frequentar a classe regular contando, quando necessário, com o auxílio de professores, e tendo a sua individualidade respeitada. As adequações específicas para o atendimento desses alunos passaram a ser uma responsabilidade compartilhada com toda a comunidade escolar, buscando meios para que eles aprendessem da melhor forma possível (SILVA; SEABRA JUNIOR; ARAÚJO, 2008). No entanto, para oferecer um ensino de qualidade a essa população com diferentes condições de deficiência, adaptações e estratégias específicas se mostraram necessárias.

No que concerne à deficiência visual - limitação óptica que, mesmo com a melhor correção, prejudica o desempenho daquele que a possui -, ela pode apresentar-se como cegueira ou baixa visão. A cegueira refere-se à perda total da visão, exigindo recursos específicos como Braille, bengalas e sinalização 
sonora; e a baixa visão, à presença de resíduos visuais que permitem empregar recursos como lupas e cores contrastantes (WINNICK, 2004).

Assim descrito, faz parecer que todo o processo se encontra efetivado e consolidado. Todavia, a inclusão da pessoa com deficiência evidenciou problemas há muito existentes no sistema educacional e que se tornaram evidentes com a chegada dessa população. Exemplos são as salas com grande número de alunos, professores desmotivados, formação inicial fragilizada, tímida formação continuada para os professores, ausência de professores auxiliares capacitados, escassez de intérpretes de LIBRAS, precarização do processo de ensino aprendizagem, entre outros (MARTÍN; SANZ SERRANO, 2007; GREGUOL; MALAGODI; CARRARO, 2018).

Esses entraves também se mostraram presentes nas aulas de Educação Física Escolar, em que se verifica a falta de acessibilidade em todo o espaço físico dentro e ao redor da escola, insuficiência de materiais, precária formação inicial do professor, além de ausência de uma formação continuada qualificatória para uma atuação alinhada aos princípios inclusivistas (AGUIAR; DUARTE, 2005; FILUS, 2011; CARVALHO; ARAÚJO, 2018; SANTOS, et al. 2020).

Especificamente no que concerne à participação de alunos com deficiência visual nas aulas de Educação Física escolar, estudos como os de Freitas, Saler e Moreira (2016), Costa e Munster (2017), Walter, Harnisch e Borella (2020) e Haegele et al. (2020), identificaram a ocorrência persistente de momentos de não participação de alunos com deficiência visual nas aulas de Educação Física devido à dificuldade docente em organizar metodologias e materiais acessíveis, com escassez de adaptações curriculares. Com isso, os autores apontaram para a necessidade de estruturação de novas pesquisas para identificar as particularidades desse processo e contribuir com a superação de uma ainda permanente exclusão escolar.

Diante desse quadro, estudos mostraram-se necessários para averiguar e orientar a implantação de uma educação inclusiva de qualidade aos alunos com deficiência visual. Contudo, em um contexto de tamanha complexidade, Carvalho (2018), ao analisar a produção acadêmica dos programas brasileiros de pósgraduação em Educação Física, identificou uma carência de estudos na área em que a própria pessoa com deficiência pudesse expor as suas impressões, necessidades e críticas. A maioria dos trabalhos estruturou-se por meio de terceiros (docentes, familiares ou alunos sem deficiência) fornecendo informações sobre essa população.

Sabendo que a inclusão, tanto no contexto educacional quanto em toda a sociedade, está relacionada a permitir uma atuação ativa da pessoa com deficiência, o objetivo da presente pesquisa foi analisar a inclusão nas aulas de Educação Física Escolar na concepção de alunos com deficiência visual. 


\section{MÉTODO}

Este estudo foi estruturado com cunho qualitativo, que, segundo os apontamentos de Thomas, Nelson e Silverman (2007), possui significância relevante nas pesquisas sociais que se realizam no espaço cotidiano, sem haver excessivo controle de variáveis a que a pesquisa quantitativa se propõe, já que o que interessa na pesquisa qualitativa é a realidade, em sua complexidade:

A pesquisa qualitativa tem como foco a "essência" do fenômeno. A visão do mundo varia com a percepção de cada um e é altamente subjetiva. Os objetivos são primeiramente a descrição, a compreensão e o significado. O pesquisador não manipula as variáveis por meio de tratamentos experimentais, mas se interessa mais pelo processo do que pelo produto (THOMAS; NELSON; SILVERMAN, 2007, p. 298).

Nesse viés, a pesquisa foi caracterizada como estudo de caso, em que um grupo é delimitado dentro de um ambiente amplo para ter suas características investigadas. Com isso, é possibilitada maior compreensão de dada realidade e sua possível forma de ocorrência na sociedade (Ludke; André, 1986)

A presente pesquisa foi realizada com dois alunos com deficiência visual do ensino médio da rede pública de Campo Grande, Mato Grosso do Sul (MS). Para iniciar a pesquisa, o projeto foi submetido ao Comitê de Ética em Pesquisa da Universidade Federal de Mato Grosso do Sul (UFMS), desenvolvendo-se em concordância com as normas do Comitê Ético sobre Experiências Humanas desta instituição - aprovado sob o número de parecer 1.863 .358 e de acordo com a declaração de Helsinki de 1995.

Como procedimentos, inicialmente foi contatada a Secretaria de Educação do Estado do Mato Grosso do Sul (MS), que consentiu com a realização da pesquisa e forneceu o contato das escolas regulares de ensino médio das cidades de Campo Grande, MS, Brasil, que possuíam alunos com deficiência visual. Ao estabelecer contato com as instituições de ensino, convidando-as para o trabalho, houve o retorno e concordância de dois alunos em participarem do estudo, um com 15 anos, e outro com 25 anos. O Termo de Consentimento foi assinado pelo próprio aluno, no caso do participante maior de idade, e pelo responsável, no caso do participante com faixa etária inferior a 18 anos. Após leitura realizada pelo pesquisador, o menor assinou o Termo de Assentimento para a participação.

Como forma de coleta de dados, foi empregada uma entrevista semiestruturada com ambos, marcada em local e horário indicados pelos participantes. A entrevista foi gravada apenas em áudio, em programa do notebook da marca Samsung, para posterior transcrição e análise. De acordo com Manzini (1990), a entrevista semiestruturada é uma forma de coleta de 
dados por meio da aplicação de um roteiro com perguntas ao participante referentes à temática principal a ser investigada, as quais podem ser complementadas por outras questões inerentes ao momento e ao contexto da entrevista. A entrevista foi conduzida pelos próprios pesquisadores em horários previamente agendados. As questões versaram sobre a condição de deficiência, sobre a sua entrada e permanência na escola, sobre as aulas de Educação Física e a sua participação nelas, bem como acerca da relação estabelecida com os colegas e professores.

Para a apreciação, os dados foram transcritos integralmente e, posteriormente, submetidos à análise de conteúdo, segundo proposta de Bardin (2011). Por meio dessa técnica, discursos diversificados foram analisados, buscando-se desvendar criticamente o que está oculto em cada fala, decompondo-os em categorias de elementos que apresentam significado para o tema estudado. Assim, três etapas foram desprendidas. Na primeira etapa, os pesquisadores realizaram uma pré-análise dos dados obtidos por meio de uma leitura exploratória das entrevistas transcritas; na segunda etapa, houve a exploração do material com a organização das principais ideias apontadas pelos respondentes; e na terceira etapa, o tratamento dos resultados com a interpretação das informações as categorizando. Com isso, quaro categorias foram elencadas para esse estudo, conforme apresentado a seguir.

\section{RESUltAdos E Discussão}

O participante aqui denominado de P1 possuía 15 anos e cursava o segundo ano do ensino médio, frequentando essa escola há dois anos, havia adquirido a condição de deficiência visual (cegueira total) há um ano, fazia acompanhamento em instituição especializada para desenvolvimento da orientação e mobilidade, espaço no qual teve o contato inicial com o esporte adaptado, especificamente o futebol de 5 . O participante aqui denominado de P2 possuía 23 anos, frequentando o Ensino de Jovens e Adultos na instituição há um ano, também havia adquirido a deficiência visual (baixa visão) há 5 anos e frequentava a mesma instituição de referência para auxiliar no processo de reabilitação. Ambos realizaram todos os níveis anteriores de ensino em instituições educacionais públicas, e, nesse nível, contavam com aulas de Educação Física.

De acordo com os relatos fornecidos pelos participantes, foi possível identificar as seguintes categorias de respostas: 
Quadro 1 - Categorias estabelecidas por meio das respostas fornecidas pela amostra

\begin{tabular}{|c|c|c|c|}
\hline $\begin{array}{c}\text { A INSTITUIÇÃO } \\
\text { ESCOLAR }\end{array}$ & $\begin{array}{c}\text { PARTICIPAÇÃO } \\
\text { NA EDUCAÇÃO } \\
\text { FÍSICA ESCOLAR }\end{array}$ & $\begin{array}{c}\text { INTERAÇÃO NAS } \\
\text { AULAS }\end{array}$ & $\begin{array}{c}\text { MUDANÇAS } \\
\text { NECESSÁRIAS }\end{array}$ \\
\hline $\begin{array}{c}\text { Escola tem que } \\
\text { estar preparada; } \\
\text { ela não estava } \\
\text { preparada }\end{array}$ & $\begin{array}{c}\text { Professor não tinha } \\
\text { qualificação; } \\
\text { vontade de } \\
\text { participar; } \\
\text { professor faz } \\
\text { atividades para que } \\
\text { eu possa participar }\end{array}$ & $\begin{array}{c}\text { Sinto-me excluído; } \\
\text { interação com } \\
\text { brincadeiras }\end{array}$ & $\begin{array}{c}\text { Interação; } \\
\text { algo que todos } \\
\text { possam fazer } \\
\text { juntos; } \\
\text { amigos sentirem na } \\
\text { pele (fazer atividade } \\
\text { adaptada) }\end{array}$ \\
\hline
\end{tabular}

Na primeira categoria de resposta - A Instituição Escola - os participantes destacaram a necessidade de a escola ser acessível. A carência de acessibilidade foi notada no relato de P1, ao afirmar "[...] acho que qualquer escola do ensino público estadual, particular, tem que tá preparada para ter pessoas com deficiência, tem que tá preparada, tipo, nunca sabe quando vai acontecer igual comigo aconteceu e eles não estavam preparados.".

A acessibilidade foi definida pela Lei Brasileira $n^{\circ} 10.098$, de 2000, como a "possibilidade e condição de alcance para utilização, com segurança e autonomia, dos espaços, mobiliários e equipamentos urbanos, das edificações, dos transportes e dos sistemas e meios de comunicação" em todos os espaços e equipamentos públicos nacionais (BRASIL, 2000, p. 01).

Contudo, uma fragilidade nesse quesito tem sido recorrente em estudos sobre a inclusão escolar (MAZZARINO; FALKENBACH; RISSI, 2011; CARVALHO; ARAÚJO, 2018; SANTOS et al., 2020). Esses estudos mostram que as instituições têm itens de acesso implantados apenas quando há a presença de algum aluno com tal demanda, e não de forma antecipatória à sua chegada, corroborando o relato de $\mathrm{P} 1$.

Segundo Duran e Prado (2006), algumas das adaptações necessárias à inclusão do aluno com deficiência visual é a inserção, em toda a escola e nos seus arredores, de piso tátil de alerta em rampas, escadas e móveis, ou locais com obstáculos, portas de cores contrastantes, além de sinalização tátil e auditiva.

No entanto, além de estruturas arquitetônicas, é imprescindível que uma participação ampla do aluno seja possível, abarcando o seu acesso e interação ativa com o conhecimento, os professores e os colegas. Nesse aspecto, compactuamos com Sassaki (1997) e Costa e Munster (2017) ao explicitar que, para a inclusão ocorrer, deve haver não apenas a acessibilidade arquitetônica, mas também a metodológica, atitudinal, de conhecimento e programática, com o emprego de adaptações que se mostrarem necessárias em cada um desses itens. 
Dessa forma, recaímos na próxima categoria mencionada - a Participação na Educação Física Escolar. Nessa segunda categoria, os sujeitos relataram gostar das aulas devido ao fato de ser uma oportunidade de praticar o esporte, como nos relataram P1: "[...] é uma aula descontraída, né? Porque ela passa... ela faz esporte com a gente, ela joga bola", e P2: "[...] as atividades que eu mais gosto, futsal... futebol e o handebol!". Contudo, afirmaram que os professores não se encontravam preparados para possibilitar a sua participação.

As aulas de Educação Física sempre foram as mais esperadas pelos alunos, pois essas não acontecem apenas em sala de aula, mas podem ser executadas na quadra ou pátio da escola. Por outro lado, por propiciarem uma interação mais contundente, elas expõem a inclusão - ou situações excludentes - de forma mais evidente na escola (FILUS, 2011).

Nesse item, os relatos tornaram evidente a ausência ou incompletude de procedimentos metodológicos direcionados à adaptação das aulas para alunos com deficiência, dificultando a sua participação, como indicado por P1: "Eu gosto, gosto de jogar, gosto de coisa, só que no momento não dá pra mim estar fazendo isso. [...] porque na escola eu não posso mais jogar, não posso mais jogar com os meninos, não jogo vôlei, não jogo mais queimada por causa referente a visão." Corroborando com essa afirmação, P2 relatou: "[...] tipo assim, tinha exercício que a gente não conseguia executar, que nem eu às vezes era pra mim imitar o outro fazendo, eu mesmo não conseguia ver o que o outro estava fazendo $[\ldots]^{\prime \prime}$.

Quando perguntamos se a professora conseguia adaptar as aulas para ele, P2 complementou a sua fala dizendo: "Não, não conseguia, até porque também ela não tinha uma qualificação assim. Tipo assim, me deu a deficiência já nos últimos bimestres, então a professora já não... tipo assim".

Haegele et al. (2020) entrevistaram dez pessoas com deficiência visual que relataram a ausência de sentimento de pertença, indicando o constante movimento de não participação nas aulas de educação física, mas demonstraram o interesse em permanecerem nesses espaços. Tal desconforto, entretanto, não deve ser desconsiderado, já que pode ser modificado a partir de alterações de estratégia e ampliação de propostas práticas para as aulas.

Furtado, Morato, Gutierrez e Alvez (2019) explicitaram que, conforme o maior grau de deficiência visual mais frequentes são os relatos de não participação durante as aulas de Educação Física, já que essa condição implica em adaptações de estratégias mais contundentes pelos professores, os quais, por sua vez, tendem a apresentar uma ainda recorrente dificuldade em propiciar a participação ativa desses alunos nas aulas.

Sem intenção de culpabilização docente, entende-se que cabe aos 
professores elaborar os seus planejamentos de forma a propiciar a participação de todos, permitindo uma atuação ativa do aluno com deficiência, e também contribuindo com a mediação para que a interação entre os discentes e a construção de conhecimento ocorra de forma benéfica a todos (SILVA; SEABRA JUNIOR; ARAÚJO, 2008).

Lacunas nessa atuação podem ser derivadas de diversos fatores. Dentre eles, Salerno (2014) elucidou que fragilidades na formação inicial não têm permitido uma plena capacitação dos futuros professores para uma atuação inclusiva eficaz. Eles encontram dificuldade em identificar as necessidades dos alunos e em implantar as adaptações necessárias nas suas aulas (GREGUOL; MALAGODI; CARRARO, 2018). Essa afirmação pode ser corroborada quando retomamos que, no estudo de Peres (2011), ao refletir sobre a inclusão de alunos com deficiência visual, a autora identificou que os professores se mostravam incapazes de construir uma inclusão com qualidade nas suas aulas devido, principalmente, à precariedade de conteúdos sobre essa condição durante os cursos de graduação, tanto referente às questões fisiológicas quanto às metodológicas e de estratégias de ensino.

Já Carvalho (2018) contribuiu com a discussão ao dizer que fatores externos desmotivam os docentes na busca por contínua qualificação e melhoria na qualidade das suas aulas. Baixos salários, desprestígio social e sobrecarga de conflitos sóciofamiliares que incidem sobre a escola são exemplos desses fatores. Contudo, destacou que, independentemente das dificuldades e contrariedades impostas na profissão docente, o professor, enquanto parte constituinte na escola, precisa se empenhar para que a sua atuação ocorra com a qualidade a que os alunos têm direito.

Assim, para Cidade e Freitas (1997), ao conhecer o seu aluno, o professor deverá fazer as adequações metodológicas levando em consideração a adaptação do material, das suas atividades e da organização da aula, assim como o tempo disponível, o espaço e os recursos materiais. Além disso, as autoras enfatizaram a necessidade de os professores empregarem constantes avaliações com o intuito de verificar se as suas ações estão sendo suficientes para estimular o desenvolvimento dos seus alunos, ou se mais adequações são necessárias, considerando os conteúdos e objetivos da Educação Física.

Apesar do contraste entre a teoria e a prática da atuação do docente, uma modificação desse cenário pode ser observada na exposição de $\mathrm{P} 1$, ao afirmar: "[...] a minha professora sempre fez atividades para eu possa participar, ela sempre colaborou comigo nessa questão. [...] ela sempre pergunta, se não tiver de acordo você me avisa, tá? Ela sempre tenta, ela sempre faz, ela sempre me ajuda!".

Sabendo que, após séculos de exclusão, a inclusão é um processo 
constituído teoricamente de forma recente e implantado legalmente apenas nas últimas décadas, as mudanças parecem estar chegando aos alunos, ainda que de forma discreta e lenta. A inclusão, enquanto processo legalmente irrevogável e indispensável enquanto direito humano, mostra-se possível a partir dessas pequenas atitudes que denotam abertura à transformação da atuação docente $e$ da prática escolar. Isso exige paciência e compreensão de que se trata de um processo vagaroso e que requer persistência e autonomia docente e cidadã para a busca de capacitação profissional e do cidadão para conviver com as inerentes diferenças de cada ser humano.

Assim, implantar o processo inclusivo engloba múltiplos fatores. Recorrendo a Omote (2003, p. 52), o autor nos remete que a inclusão é:

[...] um processo vasto, abrangente, complexo e como devendo expressar, para diferentes categorias - não só para deficientes, como também para minorias raciais e étnicas, idosos, inadaptados, desempregados, etc. - a reconstrução ou refazimento do vínculo social rompido, causador de apartação social, da sensação de não pertencimento, do sentimento de desigual, de não ser semelhante, de ser excluído não só da participação dos bens, mas da partilha com o outro.

Para além do realizar uma atividade de Educação Física, a interação com os demais alunos durante as aulas mostra-se significativa ao estar associada ao sentimento de pertencimento ao grupo. Recaindo na terceira categoria Interação nas Aulas -, observamos que, logo após estarem na condição de deficiência, alguns empecilhos começaram a aparecer em relação à interação com os colegas nas aulas práticas que contribuíram para a sua não participação nas aulas de Educação Física. Isso foi confirmado por P2, ao dizer que "[...] eu não jogava mais futsal... eu não conseguia ver mais a bola essas coisas assim. Tipo, esse negócio de escolher pro time, o pessoal já nem me escolhia mais pro time depois que eu me tornei deficiente visual!".

A inclusão fundamenta-se pelo sentimento de ser parte de um grupo. Dessa forma, em outro trecho da entrevista, questionamos os estudantes especificamente sobre o sentimento de pertencimento na Educação Física Escolar e obtivemos respostas diferentes. Na fala de P2, evidenciou-se a exclusão: "Não, me sinto excluído, me sinto diferente dos outros demais. Assim não me dava ânimo para fazer os outros esportes e tudo mais. Não, eu me sinto muito excluído!" Porém, na resposta de P1, observamos que existe a socialização entre os alunos, bem como o auxílio em determinados momentos. Ele nos diz que a sua relação com eles é de brincadeira e que, sempre que vai haver alguma atividade, os colegas já falam: "[...] ó ó ó ele vai participar em gente, ajuda aí ele, né!".

Spencer-Cavaliere e Watkinson (2010) buscaram no discurso dos alunos com deficiência o entendimento sobre o processo de inclusão nas atividades 
físicas desenvolvidas na escola. Na idade de 8 a 12 anos, os participantes da pesquisa indicaram que o sentimento de inclusão perpassa a relação estabelecida com os colegas, já que ser chamado para o jogo, sentir-se como participante legítimo da proposta e ter amigos foram as categorias destacadas pelos estudantes.

Tais ocorrências confirmam a discussão acima sobre o momento de transição pelo qual estamos passando em relação à inclusão educacional, em que procedimentos e concepções há séculos cristalizados passam a ser questionados e reconstruídos. Segundo Rodrigues (2003), a escola tradicional, que valorizava a homogeneidade, exigindo que os alunos se adaptassem a uma forma padronizada de escolarização, sucumbiu a um novo modelo fundamentado na ideia de heterogeneidade, que passou a compreender e a respeitar as diferenças nas abordagens pedagógicas.

Vivenciamos, portanto, um momento de mudanças, tema este da quarta e última categoria observada nos relatos dos alunos entrevistados - Mudanças Necessárias.

Perguntamos aos alunos o que eles mudariam nas aulas da sua turma para uma melhor participação nas aulas de Educação Física. Ambos afirmaram que todos deveriam participar, como na sugestão de P2, que disse: "[...] a interação, que nem o professor interagir mais assim, tanto aqueles que enxergam que tão lá e são deficientes possam fazer juntos, entendeu? [...] os deficientes não se sintam excluídos em relação aos que vê todos possam fazer e todos possam gostar".

Como sugestão de mudança nas aulas da sua turma, P1 sugeriu colocar os seus colegas na mesma condição de deficiência dele: "[...] uma demonstração de como se joga o Futebol de 5, igual a minha professora mesmo fez isso, colocou eles para jogar de guizo. De olhos fechados, né? [...] ver como que é, como que são as coisas. [...] sentir na pele." Porém, a professora apresentou uma atividade para que a sua turma vivenciasse um esporte adaptado em apenas uma ocasião isolada, e ele gostaria que isso acontecesse mais vezes.

O aluno P1 mostrou uma concepção estruturada e consciente em relação à sua condição, entendendo que todos - inclusive a pessoa com deficiência possuem potencialidades, afirmando: "[...] posso fazer tudo, só que tem que estar adaptado pra mim.".

Ao citar o Futebol de 5 - esporte adaptado criado especificamente para a população com deficiência visual -, o aluno recorreu a um dos conteúdos de Educação Física que vem contribuindo e oferecendo possibilidades para a pessoa com deficiência - o Esporte. 
Conforme discorreu Heil (2008), a prática esportiva, além de trazer vários benefícios fisiológicos, também ajuda a vencer as limitações impostas não só pela deficiência, mas também pela sociedade.

No entanto, devemos destacar que o esporte é apenas um dos variados conteúdos que compõem a Educação Física, sendo todos eles facilitadores da inclusão quando de uma intervenção adequada do docente. Segundo Carvalho e Araújo (2018), o esporte, conjuntamente à dança, ao jogo, à luta, à ginástica e às demais atividades corporais, quando exploradas com caráter de vivência e construção de conhecimento sócio-histórico-cultural, contribuem com a participação de todos e com a efetivação da inclusão no contexto escolar.

O jogo, com ludicidade e regras flexíveis, pode proporcionar situações de afetividade e interação (GIL; SCHEEREN; LEMOS; FERREIRA, 2002); na luta, pode-se explorar a possibilidade de utilização de diversos meios para a realização das técnicas, expondo a possibilidade de participação de todos (GOMES, 2008); na ginástica, é possível beneficiar-se do desenvolvimento da criatividade e da expressão como uma forma de cooperação e afetividade (MAYEDA; ARAÚJO, 2004); e, na dança, pode-se proporcionar ludicidade, estímulo à participação de todos, vivência cultural com conscientização e criação própria de movimentos corporais e liberdade de expressão individual (WINNICK, 2004).

Averiguamos, portanto, que, quando da chegada de um aluno com deficiência visual, os professores e a escola demonstraram estar despreparados, ausentes de recursos e procedimentos necessários para recebê-los. Mas, aos poucos, vão buscando por adequações. Especificamente em relação à Educação Física, os alunos com deficiência visual relataram gostar e querer participar da aula, entendendo-a como um momento em que desenvolvem um sentimento de pertencimento ao grupo, uma vez que as atividades ocorrem de forma coletiva e propiciam interações socioafetivas. Os alunos clamam pela concretização de ações que já estão estabelecidas legalmente, como pela Lei de Diretrizes e Bases da Educação (BRASIL, 1996) e a Lei Brasileira de Inclusão (2015), que garantem a participação ativa do aluno com deficiência no contexto escolar, com a adaptação da escola a todas as necessidades dos seus alunos para possibilitar a sua atuação plena.

Isto posto, esse estudo nos mostra a necessidade de darmos voz aos alunos com deficiência, a fim de conhecer os seus anseios, perguntar sobre as suas preferências e possibilidades em relação às adaptações, e construir coletivamente as adequações, uma vez que os próprios alunos exemplificam possibilidades de intervenções para facilitar a sua participação e interação, como vivências de deficiência com os demais alunos da turma. 


\section{CONSIDERAÇÕES FINAIS}

A relevância da inclusão nas aulas de Educação Física Escolar não diz respeito somente à possibilidade do aluno participar de uma atividade de aula específica, mas incorporá-lo plenamente à aula e à turma de alunos. Para isso, é preciso, sobretudo, ouvir o aluno com deficiência, atentando-se às suas particularidades, sugestões e opiniões. Com esse estudo, foi notório que a inclusão do aluno com deficiência visual nas aulas de Educação Física se encontra em processo de construção, com pontos positivos entremeados por dificuldades em sua consolidação. A falta de acessibilidade arquitetônica ainda se mostrou recorrente, bem como momentos de não participação dos alunos durante as aulas devido à sua condição. Apesar de um dos participantes relatar se sentir acolhido pelo grupo e ter as atividades adaptadas pela professora, o outro ainda se diz excluído e carente de atuação docente para facilitar sua participação. Os alunos clamam por maior participação nas aulas, por uma inclusão alicerçada pela compreensão dos colegas sobre a sua condição.

Um fator que podemos averiguar nessa pesquisa é a importância de uma formação docente - inicial e continuada - para que o professor reflita continuamente acerca dos desafios inerentes ao magistério e à questão inclusiva, buscando bases teóricas para que as suas intervenções práticas sejam eficazes e realizando as adaptações que se mostrarem necessárias.

Notamos algumas contradições nas percepções dos participantes da pesquisa. Esse fato pode denotar de fatores múltiplos que extrapolam o alcance dessa pesquisa, como o contexto vivenciado por cada participante e até mesmo o presente momento de transição, em que o processo inclusivo tem exigido a reconstrução das estruturas físicas, materiais e procedimentais de todos os ambientes e sujeitos envolvidos.

Nota-se, por fim, a necessidade dos estudos acadêmicos sobre a inclusão na Educação Física Escolar deslocarem o seu foco da já bem explorada análise observadora do pesquisador em relação à existência ou não da inclusão nas aulas para pesquisas em que haja um espaço que permita às próprias pessoas com deficiência expor o seu ponto de vista sobre esse processo, superando, assim, a tendência de as suas necessidades serem verificadas e expostas por terceiros. Pesquisas contínuas são urgentes para que possamos dar voz aos silenciados por muitos séculos na nossa sociedade, assim como para implantar as ações que eles nos mostram ser necessárias. 


\section{REFERÊNCIAS}

AGUIAR, João Serapião; DUARTE, Edson. Educação Inclusiva: Um Estudo na Área da Educação Física. Marília. Revista Brasileira de Educação Especial, v.11, n. 2, p. 223-240, ago. 2005. Disponível em:

http://www.scielo.br/scielo.php?script=sci arttext\&pid=S1413-

65382005000200005\&lng=en\&nrm=iso. Acesso em: 01 ago. 2019.

BARDIN, Laurence. Análise de conteúdo. São Paulo: Edições 70, 2011.

BRASIL. Declaração de Salamanca. Sobre Princípios, Politicas e Práticas na Área das Necessidades Educativas Especiais. Diário Oficial [da] República Federativa do Brasil, Brasília, DF, 1994a. Disponível em:

http://portal.mec.gov.br/seesp/arquivos/pdf/salamanca.pdf. Acesso em: 12 jan. 2019.

. Lei $n^{\circ}$ 9.394, de 20 de dezembro de 1996. Estabelece as diretrizes e bases da educação nacional. Diário Oficial [da] República Federativa do Brasil, Brasília, DF, 20 dez. 1996. Disponível em: www.planalto.gov.br/ccivil 03/leis/L9394.htm. Acesso em: 14 jan. 2019.

. Lei no 10.098, de 19 de dezembro de 2000. Estabelece normas gerais e critérios básicos para a promoção da acessibilidade das pessoas portadoras de deficiência ou com mobilidade reduzida, e dá outras providências. Diário Oficial [da] República Federativa do Brasil, Brasília, 19 dez. 2000. Ano CXXXVIII No 244-E. Disponível em:

http://www6.senado.gov.br/legislacao/ListaTextoIntegral.action?id=218628. Acesso em: 30 ago. 2010.

. Lei $n^{\circ} 13.146$, de 06 de julho de 2015. Institui a Lei Brasileira de Inclusão da Pessoa com Deficiência (Estatuto da Pessoa com Deficiência). Diário Oficial [da] República Federativa do Brasil, Brasília, DF, 6 jul. 2015. Disponível em: < https://www.planalto.gov.br/ccivil 03/ ato2015-2018/2015/lei/l13146.htm. Acesso em: 02 de fev. de 2016.

CARVALHO, Camila Lopes de. Reflexões sobre a inclusão na educação física escolar: a tríade legislação, conhecimento acadêmico e prática profissional. 2018. 323f. Tese (Doutorado em Educação Física) - Faculdade de Educação Física, Universidade Estadual De Campinas, Campinas, 2018.

CARVALHO, Camila Lopes de; ARAÚJO, Paulo Ferreira de. Inclusão escolar de alunos com deficiência: interface com os conteúdos da Educação Física. Educación Física y Ciencia, Buenos Aires, v.20, n.01, p. 41-56, ene. 2018. Disponível em:

http://www.efyc.fahce.unlp.edu.ar/article/view/EFyCe041. Acesso em: 16 mai. 2018.

CIDADE, Ruth Eugênia; FREITAS, Patrícia Silvestre. Educação Física e Inclusão:

Considerações para a Prática Pedagógica na Escola. Revista Integração - MEC, p.1-7,

1997. Disponível em: http://www.rc.unesp.br/ib/efisica/sobama/sobamaorg/inclusao.pdf. Acesso em: 01 ago. 2019.

COSTA, Camila de Moura; MUNSTER, Mey de Abreu van. Adaptações Curriculares nas Aulas de Educação Física Envolvendo Estudantes com Deficiência Visual. Revista Brasileira de Educação Especial, Marília, v. 23, n. 3, p. 361-376, Sept. 2017. Disponível em: http://www.scielo.br/scielo.php?script=sci arttext\&pid=S1413-

65382017000300361\&lng=en\&nrm=iso. Acesso em: 01 jul. 2020.

DURAN, Mônica Geraes; PRADO, Romeiro de Almeida. Acessibilidade nos estabelecimentos de ensino. In. III SEMINÁRIO NACIONAL DE FORMAÇÃO DE GESTORES 
E EDUCADORES - EDUCAÇÃO INCLUSIVA: DIREITO A DIVERSIDADE. ENSAIOS PEDAGÓGICOS. Brasília. Anais... Brasília: Ministério da Educação, 2006. v. 1, p. 137142.

FREITAS, Michelle Gomes; SALES, Zenilda Nogueira; MOREIRA, Ramon Missias. Representações de alunos com deficiência visual sobre as aulas de educação física escolar. Revista Eletrônica de Educação, v. 10, n. 1, p. 100-109, 2016.

FILUS, Josiane Freitas. Amarrações e arrumações na inclusão do município de Hortolândia-SP. 2011. 199f. Tese (Doutorado em Educação Física) - Faculdade de Educação Física. Universidade Estadual de Campinas, Campinas, 2011.

FONSECA, Victor. Educação Especial. Porto Alegre: Artes Médicas, 1991.

FURTADO, Otávio Luis Piva Da Cunha; MORATO, Marcio Pereira; GUTIERREZ, Gustavo Luis; ALVES, Maria Luiza Tanure. A participação de jovens com deficiência visual em aulas de Educação Física: experiências na rede regular e em instituições especializadas. Pensar a Prática, v. 22, 18 abr. 2019.

GIL, João Pedro Alcântara; SCHEEREN, Carine; LEMOS, Helen Denise Daneres; FERREIRA, Simone de Mamann. O significado do jogo e do brinquedo no processo inclusivo: conhecendo novas metodologias no cotidiano escolar. Revista Educação Especial, Santa Maria, v. 1, n.20, p.75-88, 2002. Disponível em: https://periodicos.ufsm.br/educacaoespecial/article/view/5109. Acesso em: 01 ago. 2019.

GOMES, Mariana Pimentel. Procedimentos pedagógicos para o ensino de Lutas: contextos e possibilidades. 2008. 139f. Dissertação (Mestrado em Educação Física) - Faculdade de Educação Física, Universidade Estadual de Campinas, Campinas, 2008.

GREGUOL, Márcia; MALAGODI, Bruno Marson; CARRARO, Attilio. Inclusão de alunos com deficiência nas aulas de educação física: atitudes de professores nas escolas regulares. Revista Brasileira de Educação Especial, v. 24, n.1, p. 33-44, 2020. Disponível em: http://www.scielo.br/pdf/rbee/v24n1/1413-6538-rbee-24-01-0033.pdf. Acesso em: 06 jul. 2020.

HAEGELE, Justin; HODGE, Samuel R.; ZHU, Xihe; HOLLAND, Steven K; WILSON, Wesley J. Understanding the Inclusiveness of Integrated Physical Education From the Perspectives of Adults With Visual Impairments. Adapted Physical Activity Quarterly:APAQ, v.37, n. 2, p. 141-49, 2020. Disponível em: https://doi.org/10.1123/apaq.2019-0094. Acesso em: 06 jul. 2020.

HEIL, Edineia. A percepção de atletas com deficiência visual sobre o esporte adaptado. 2008. Monografia (Bacharel em Psicologia) - Centro de Ciências da Saúde, Universidade do Vale do Itajaí, Itajaí, 2008.

LUDKE, Menga; ANDRÉ, Marli. Pesquisa em educação: abordagens qualitativas. São Paulo, Brasil: EPU, 1986.

MANZINI, Eduardo José. A entrevista na pesquisa social. Didática, v. 26/27, n. 1, p. 149$158,1990$.

MARTÍN, Durán; SANZ SERRANO, Alberto. Dificultades del Profesorado de Educación Física de Educación Secundaria ante el alumno con discapacidad. Revista Internacional de Medicina y Ciencias de la Actividad Física y el Deporte, Madrid, vol. 7, n. 27, p. 203-231, set, 2007. Disponível em: http://cdeporte.rediris.es/revista/revista27/artdificultades41b.htm Acesso em: 13 ago. 2019. 
MAZZARINO, Jane Márcia; FALKENBACH, Atos; RISSI, Simone. Acessibilidade e inclusão de uma aluna com deficiência visual na escola e na educação física. Revista Brasileira de Ciências do Esporte, v. 33, n. 1, p. 87-102, 2011. Disponível em:

https://dx.doi.org/10.1590/S0101-32892011000100006. Acesso em: 02 ago. 2019.

MAYEDA, Silvia; ARAÚJO, Paulo Ferreira. Uma proposta de ginástica geral para deficientes físicos. Movimento \& Percepção, v.4, n.4/5, p.55-73, 2004.

OMOTE, Sadão. Algumas tendências (ou modismos?) recentes em educação especial e a Revista Brasileira de Educação Especial. Revista Brasileira de Educação Especial, Piracicaba, v.9, n.1, p.25-38, 2003.

PERES, Lívia. Comportamento motor no contexto escolar e familiar da criança com deficiência visual. 2011. 114f. Dissertação (Mestrado em Ciências do Movimento Humano) - Centro de Ciências da Saúde e do Esporte, Universidade do Estado de Santa Catarina, Florianópolis, 2011.

RODRIGUES, David. Perspectivas sobre a Inclusão: da Educação à Sociedade. Porto: Editora Porto, 2003.

SANTOS, Mariselma Oliveira dos; CARVALHO, Camila Lopes de; ARAÚJO, Paulo Ferreira de; SALERNO, Marina Brasiliano. Educação Física Escolar e Inclusão: Um Estudo de Caso No Brasil Sob a Óptica Do Modelo Bioecológico." Motrivivência, v.32, n.62, p 01-21, 2020. Disponível em: https://doi.org/10.5007/2175-80402.2020e67312. Acesso em: 06 jul. 2020.

SALERNO, Marina Brasiliano. A Formação em Educação Física e o Trabalho com Pessoas com Deficiência: Percepção Discente, 2014. Tese (Doutorado em Educação Física) Faculdade de Educação Física, Universidade Estadual de Campinas, Campinas, 2014.

SASSAKI, Romeu Kazuma. Inclusão: Construindo Um a Sociedade Para Todos. 3 a edição. Rio de Janeiro: WVA, 1997.

SILVA, Rita de Fátima da; SEABRA JUNIOR, Luiz; ARAÚJO, Paulo Ferreira de. Educação Física Adaptada no Brasil: da história à inclusão educacional. São Paulo: Phorte, 2008.

SMITH, Deborah. Introdução à Educação Especial: ensinar em tempos de inclusão. 5. ed. Porto Alegre: Artmed, 2008.

SPENCER-CAVALIERE, Nancy; WATKINSON, Jane. Inclusion Understood from the Perspectives of Children with Disability. Adapted Physical Activity Quarterly, v.27, n.4, p. 275-93, 2010. Disponível em: https://doi.org/10.1123/apaq.27.4.275. Acesso em: 06 jul. 2020.

THOMAS, Jack; NELSON, Jerry; SILVERMAN, Sthephen. Métodos de pesquisa em atividades físicas. Porto Alegre: Artmed, 2007.

WALTER, Lizete Wasem; HARNISCH, Gabriela Simone; BORELLA, Douglas Roberto. Atendimento educacional especializado envolvendo alunos com deficiência visual na educação física escolar. Movimento, Porto Alegre, p. 26020, mar. 2020. Disponível em: https://www.seer.ufrgs.br/Movimento/article/view/97282. Acesso em: 01 jul. 2020.

WINNICK, Joseph. Educação física e esportes adaptados. Barueri, Brasil: Manole, 2004. 